\title{
Anti-gpA33/CD3 Monoclonal Antibody MGD007
}

National Cancer Institute

\section{Source}

National Cancer Institute. Anti-gpA33/CD3 Monoclonal Antibody MGD007. NCI

Thesaurus. Code C118442.

An anti-glycoprotein A33 (gpA33)/anti-CD3 bispecific humanized monoclonal antibody with potential immunostimulatory and antineoplastic activities. Anti-gpA33/CD3 monoclonal antibody MGD007 possesses two antigen-recognition sites, one for the CD3 complex, a group of T-cell surface glycoproteins that complex with the T-cell receptor (TCR), and one for gpA33, a tumor-associated antigen (TAA) overexpressed on the surface of certain tumor cells. Upon administration of MGD007, this bispecific antibody simultaneously binds to both CD3-expressing T-cells and gpA33-expressing cancer cells, thereby crosslinking cytotoxic T-lymphocytes (CTLs) to gpA33-expressing tumor cells. This may result in CT L-mediated cell lysis of the crosslinked tumor cells. The gpA33 antigen, a member of the immunog lobulin superfamily, is expressed in certain malignancies, including colon and gastrointestinal cancers. 